\title{
Effect of bimodal powder blends on part density and melt pool fluctuation in laser powder bed fusion
}

\author{
Lukas Haferkamp ${ }^{1,2}\left(\right.$ D) Simon Liechti ${ }^{2} \cdot$ Adriaan Spierings $^{1} \cdot$ Konrad Wegener $^{2}$
}

Received: 7 September 2020 / Accepted: 5 April 2021 / Published online: 17 April 2021

(c) The Author(s) 2021

\begin{abstract}
The final part density in laser powder bed fusion is influenced by the powder particle size distribution. Too fine powders are not spreadable, and too coarse powders cause porosity. Powder blends, especially bimodal ones, can exhibit higher packing densities and changes in flowability compared to their monomodal constituents. These properties can influence final part density. Therefore, the influence of bimodal powder on final part density was investigated. Two gas atomized 316L (1.4404) powders with a D50 of $20.3 \mu \mathrm{m}$ and $60.3 \mu \mathrm{m}$ were blended at weight ratios of 3:1, 1:1, and 1:3, and the original and blended powders were processed. The results show that the final part porosity increases almost linearly with an increasing volume fraction of coarse powder. Furthermore, the final part density is independent of powder bulk density and flowability. Measurements of the top surface show that an increase of part porosity by coarse powder is caused by an increase in melt pool fluctuation, which in turn causes irregular solidified scan tracks. Additionally, the results show that the powder segregation during coating is stronger for the bimodal powder; however, no influence of the segregation on the part density could be found.
\end{abstract}

Keywords LPBF · Powder · Bimodal · Part density · Additive manufacturing · Laser powder bed fusion

\section{Introduction}

Final part density in laser powder bed fusion (LPBF) is influenced by the particle size distribution (PSD) of the feedstock material $[1,2]$. Too fine powders cannot be spread in LPBF. Pleass and Jothi [3] have shown that powder with a D90 below $10 \mu \mathrm{m}$ becomes unusable due to overwhelming cohesive forces. Too coarse powders are also unsuitable for LPBF, as they lead to porosity $[2,4]$ and low surface quality [4]. Therefore, the typical particle sizes for LPBF are between 10 and $60 \mu \mathrm{m}$ [5].

It is an industrial practice to blend different batches of powder during the refilling of LPBF machines. Properties of powder blends can, however, differ from those of the original powders. The powder packing density influences

Lukas Haferkamp

haferkamp@inspire.ethz.ch

1 Inspire, Innovation Center for Additive Manufacturing Switzerland (icams), Lerchenfeldstrasse 3, 9014 St. Gallen, Switzerland

2 Institute of Machine Tools and Manufacturing (IWF), Swiss Federal Institute of Technology, ETH Zürich, Leonhardstrasse 21, 8092 Zurich, Switzerland the final part density [6-8], and McGeary [9] has shown that the packing density of bimodal blends of powders is higher than that of monomodal ones. Furthermore, the spreadability of bimodal powders can differ from that of monomodal ones [10], and spreadability, in turn, may influence the final part properties and can impede the final part density [11], which is a major quality metric of LPBF [12]. Therefore, the effect of powder blends on part properties, especially part density, is investigated.

Coe and Pasebani [13] investigated the influence of bimodal powders on the final part density in LPBF. They compared a monomodal $316 \mathrm{~L}$ powder $(\mathrm{D} 50=36.31 \mu \mathrm{m})$ with a bimodal powder with two modes at $36.31 \mu \mathrm{m}$ and $5.52 \mu \mathrm{m}$. Their results show a higher tap density of the bimodal powder and an increase of the part density of up to $2 \%$ points for processing parameters with low volumetric energy density. No systematic difference in part density was found for high energy densities. Chen et al. [10] simulated the spreading of powders and found that bimodal powders might, despite their high bulk packing density, yield no improvement of the powder density in thin layers. They attribute this to cavities in the powder bed, which form during the coating process. Jeon et al. [14] investigated the effect of blends of spherical and non-spherical 


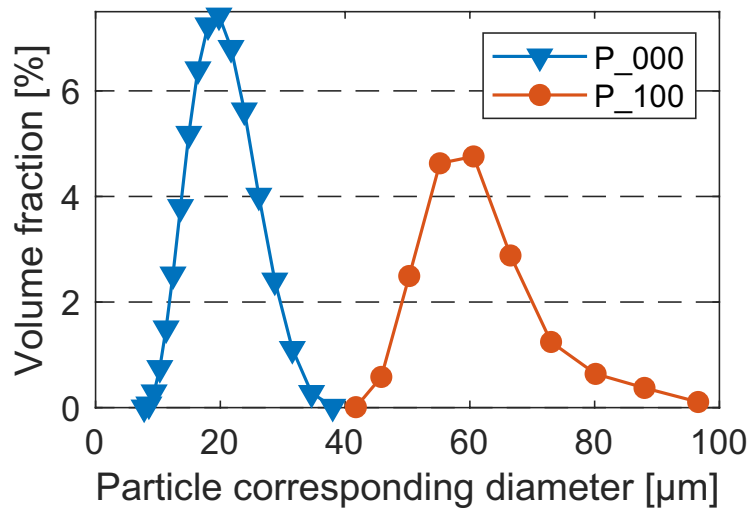

Fig. 1 PSDs of the initial powders, measured by laser diffraction

Table 1 Weight fraction of the bimodal powders blends

\begin{tabular}{lllllc}
\hline & P_000 & P_025 & P_050 & P_075 & P_100 \\
\hline $\begin{array}{l}\text { Weight } \\
\text { fraction of }\end{array}$ & 100 & 75 & 50 & 25 & 0 \\
$\begin{array}{l}\text { P_000 [\%] } \\
\begin{array}{l}\text { Weight } \\
\text { fraction of }\end{array}\end{array}$ & 0 & 25 & 50 & 75 & 100 \\
P_100 [\%] & & & & & \\
\hline
\end{tabular}

powders on the part density and found that the part porosity increases with the degree of particle size misfit of the powders. Gürtler et al. [15] simulated LPBF with blends of fine and coarse powders and found that powders with small particles compensate defects in the powder layer better than coarse powders.

This study investigates the effect of powder blends on part density in more detail. Therefore, bimodal blends of fine $(\mathrm{D} 50=20.3 \mu \mathrm{m})$ and coarse (D50 =60.3 $\mu \mathrm{m}) 316 \mathrm{~L}(1.4404)$ powder are created, characterized, and then processed. The density of the final parts is then measured, and the melt pool fluctuation is measured and compared for mono- and bimodal powders. Eventually, the powder segregation during coating is investigated.

\section{Materials and methods}

\subsection{Experimental setup}

The two gas atomized 316L (1.4404) powders, with their PSDs shown in Fig. 1, were blended to create the bimodal powders in Table 1. Both initial powders have narrow PSD and a D50 of $20.3 \mu \mathrm{m}$ and $60.3 \mu \mathrm{m}$, respectively. The coarse powder is much smaller than the expected effective layer thickness, i.e. $150 \mu \mathrm{m}[16,17]$, and can, therefore, be processed in LPBF.
Table 2 Parameters used for powder processing

\begin{tabular}{lll}
\hline Parameter & Unit & Value \\
\hline Laser power & {$[\mathrm{W}]$} & 180 \\
Hatch & {$[\mu \mathrm{m}]$} & 75 \\
Layer height & {$[\mu \mathrm{m}]$} & 30 \\
Scan speed & {$[\mathrm{mm} / \mathrm{s}]$} & $1000,1500,2000,2500,3000$ \\
Shielding gas & - & Nitrogen \\
Coating technology & - & Brush \\
Beam diameter, 1/e $\mathrm{e}^{2}$ & {$[\mu \mathrm{m}]$} & 105 \\
$\quad$ (measured) & & \\
Coating speed & {$[\mathrm{mm} / \mathrm{s}]$} & 100 \\
Scanning strategy & - & $90^{\circ}$ alternating, parallel to the \\
& & sides of the cube \\
\hline
\end{tabular}

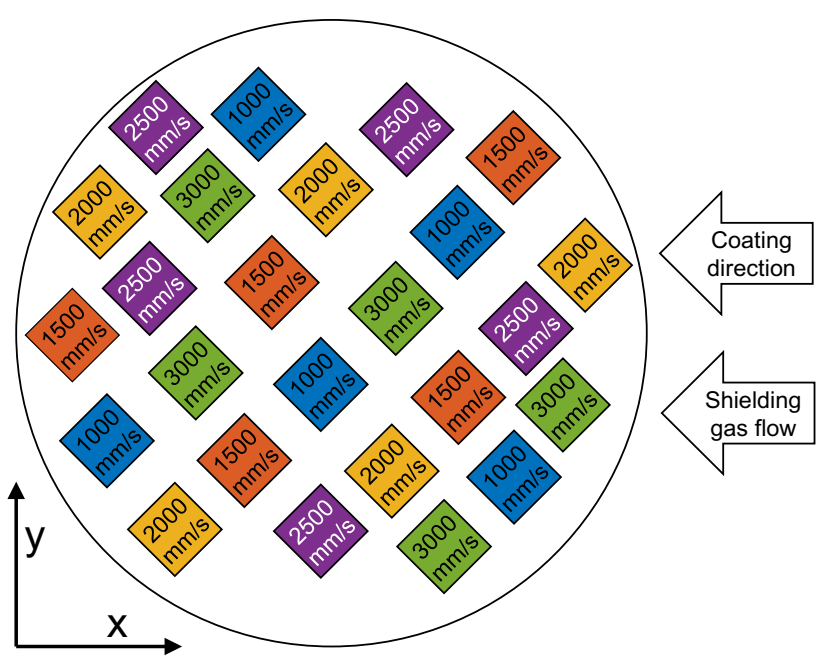

Fig. 2 Position of cubes on the build platform with scan speed indicated for each cube

The powders were blended with the weight ratios listed in Table 1. Each powder designation was chosen to reflect the weight fraction of the coarse powder in percent, e.g. P_025 is a blend of $25 \%$ coarse and $75 \%$ fine powder, and P_100 consists of $100 \%$ coarse powder. The blending was done for $2 \mathrm{~h}$ in a rotating cylindrical drum. Afterward, the homogeneity of the mixture was verified on a Leica DM6 light microscope.

All five powders in Table 1 were processed on a Concept Laser M2, using the parameters listed in Table 2. Five $10 \times 10 \times 10 \mathrm{~mm}$ cubes were built at five scan speeds, resulting in 25 cubes per powder. These cubes were evenly distributed on the build platform to compensate for locationdependent differences in part density, as is documented in Fig. 2 with a coordinate system according to ISO/ASTM 52900 [18]. Cubes downstream of the shielding gas flow were scanned first for each layer, i.e. the scanning order was 
from left to right in Fig. 2. A custom-made insert to reduce the build platform to $95 \mathrm{~mm}$ in diameter was used. The powder was sampled from the build chamber and overflow region after the build cycle to measure the powder segregation during the coating process.

\subsection{Powder characterization}

The particle shape was measured using a Leica DM6 light microscope. Images were taken by transmitted light microscopy and then processed in MATLAB, where all agglomerates were manually removed until 3000 particles per powder were identified. The circularity $f_{\text {circ }}$ was calculated according to the equation used by Bouwman et al. [19] as $f_{\text {circ }}=(4 \pi A) / P^{2}$, where $A$ is the area and $P$ the perimeter of the projected particle. The apparent density $\rho_{a}$ and tap density $\rho_{t}$ of each powder were measured three times according to ASTM B417-18 [20] and ASTM B527-15 [21], respectively. The Hausner ratio $H$ was then calculated as the ratio of tap to apparent density $H=\rho_{t} / \rho_{a}$. The powder flowability was also assessed in a REVOLUTION Powder Analyzer (RPA) by Mercury Scientific Inc. The avalanche angle and surface fractal were measured according to the procedure described by Spierings et al. [11] with the measurement principle depicted in Fig. 3.

A description of the calculation of the avalanche angle and surface fractal was given by Amado [22]. The avalanche angle is the angle between a linear regression line of the free powder surface in the left half of the drum and the horizontal before the start of a powder avalanche, as shown in Fig. 3. According to Amado [22] and Spierings et al. [11], the surface fractal corresponds to the fractal dimension of the free powder surface and is a measure for the roughness of the powder surface. The measurement is performed after each avalanche. A smooth powder surface results in a surface fractal close to one, more rough and jagged powder surfaces will result in higher surface fractals.

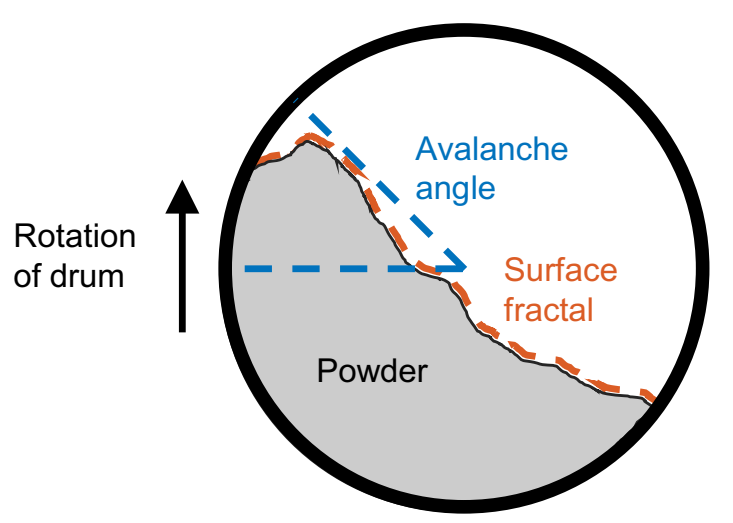

Fig. 3 Avalanche angle and surface fractal measurement in an RPA [22]

\subsection{Part characterization}

The part density was measured with the Archimedes principle in acetone. Images of the part surfaces were taken with a GelSight Benchtop system by GelSight Inc. Five cubes, each from a different powder, built with a scan speed of $1000 \mathrm{~mm} / \mathrm{s}$ were analyzed in more detail. To measure the melt pool, the parts were cut perpendicular to the scan direction of the top layer, polished, and etched. A $10 \mathrm{~mm}$ wide cube with a hatch of $75 \mu \mathrm{m}$ results in 134 melt pools along the top surface in each cross-section for which the 114 inner melt pools were sampled. The melt pool depth, melt pool area, and scan track width, as shown in Fig. 4, were then measured in a semi-automatic MATLAB script based on the MATLAB image segmentation toolbox for each melt pool.

\section{Results and discussion}

The D10, D50, and D90 of P_000 and P_100, as well as their particle circularity, are shown in Table 3 . The D-values are not displayed for P_025, P_050, and P_075, as they are not suited to describe bimodal powders. The circularity of both powders is similar. Any influence of the particle circularity will therefore be neglected hereinafter.

Figure 5 shows the cumulative PSD of all powders. Also, it shows the theoretical PSDs of P_025, P_050, and P_075, based on their respective mixing ratio of $P_{-} 000$ and $P_{-} \_100$. A qualitative evaluation of the homogeneity of $\mathrm{P}_{-} 025$, P_050, and P_075 with a light microscope showed good mixing of the powders.

The tap density, apparent density, and Hauser ratio of all powders are displayed in Fig. 6 . The tap density of all blended powders is higher than that of the monomodal powders. The higher packing density of blended powders is caused by the better arrangement of particles, as it has been shown by McGeary [9], Du et al. [23], and Karapatis

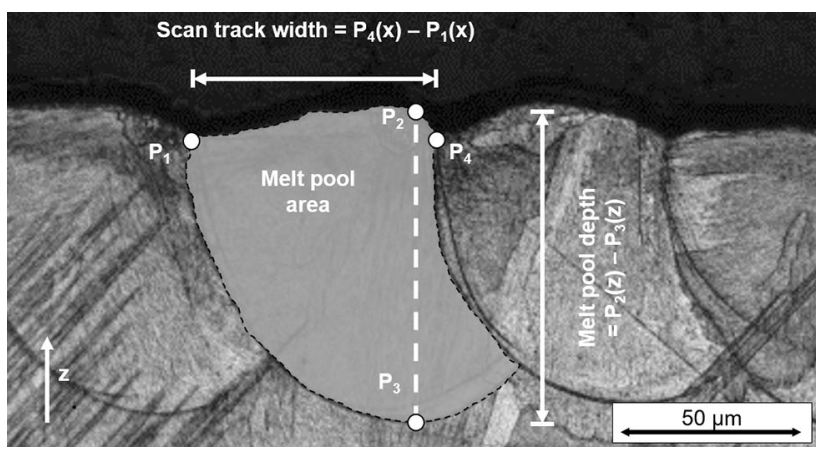

Fig. 4 Measured melt pool dimensions; P1: left contact point of the melt pool and the surface, P2: the intersection of a vertical line through P3 and the surface, P3: deepest point of the melt pool, P4: right contact point of the melt pool and the surface 
Table 3 D10, D50, D90, distribution-width (D90-D10), and circularity of P_000 and P_100, volume fraction

\begin{tabular}{lllllll}
\hline & D10 $[\mu \mathrm{m}]$ & D50 $[\mu \mathrm{m}]$ & D90 $[\mu \mathrm{m}]$ & D90-D10 $[\mu \mathrm{m}]$ & $\begin{array}{l}\text { Circularity } \\
\text { mean }\end{array}$ & Circularity STD \\
\hline P_000 & 14.2 & 20.3 & 27.7 & 13.5 & 0.96 & 0.08 \\
P_100 & 50.9 & 60.3 & 75.4 & 24.5 & 0.94 & 0.15 \\
\hline
\end{tabular}

Fig. 5 Cumulative PSD of the original and blended powders and the theoretical distributions of the blended powders based on the PSD of P_000 and P_100

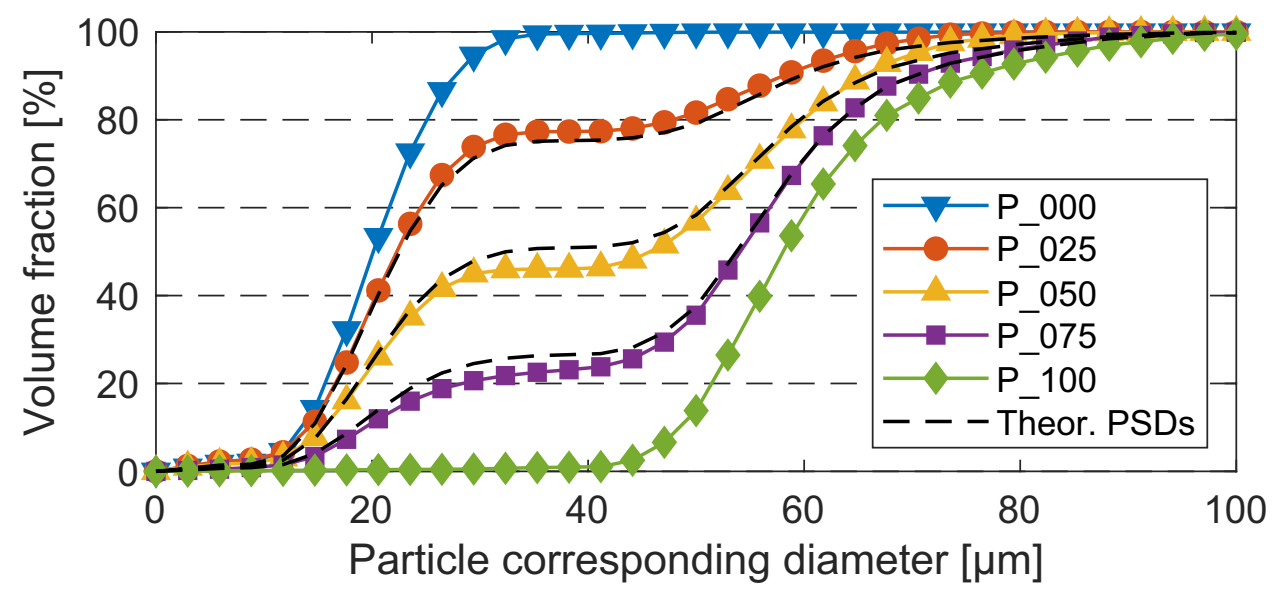

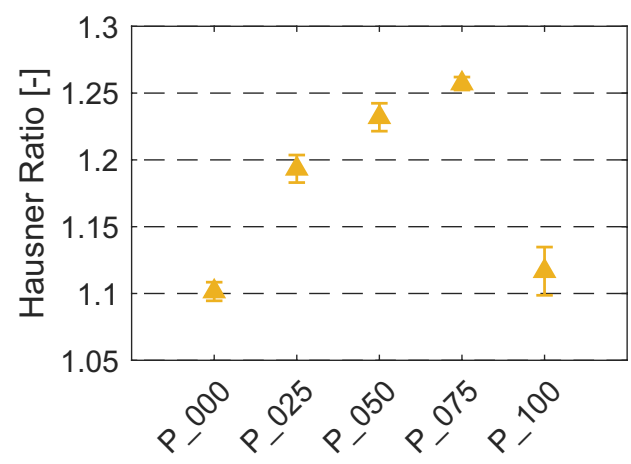

Fig. 6 Mean of tap density, apparent density, and Hauser ratio with standard deviation

Fig. 7 Mean of avalanche angle and surface fractal with standard deviation
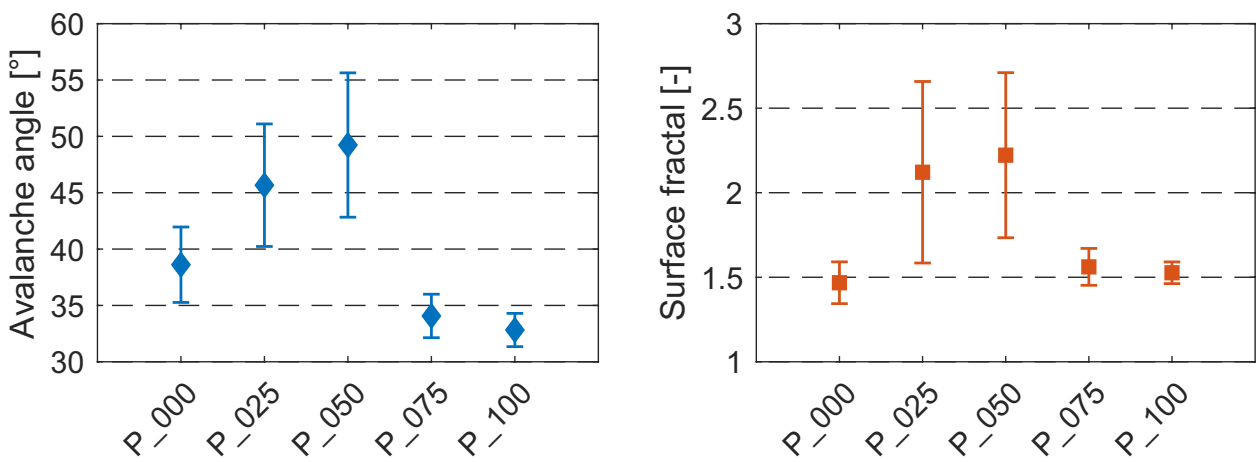

et al. [24] for bimodal powders. The Hausner ratios of all blended powders are higher than the Hausner ratios of $P \quad 100$ and $P$ 000. The avalanche angle and surface fractal, displayed in Fig. 7, indicate low flowability for P_025 and P_050. P_075, however, shows only a little difference compared to the values of $P_{-} 000$ and $P_{-} 100$.

Figure 8 shows part densities for all powders at all scan speeds with a regression line for each scan speed. The part 


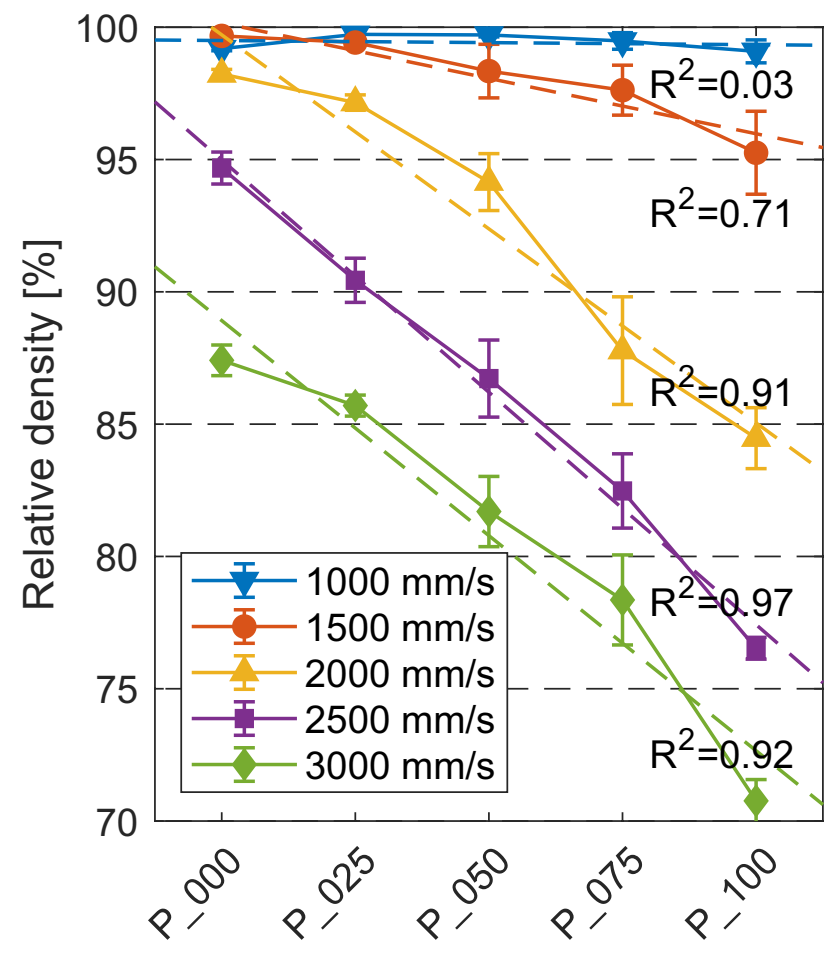

Fig. 8 Mean part densities with standard deviation plotted against powder type with linear regression lines and coefficient of determination $R^{2}$

density decreases, as typical for LPBF [2, 25], with increasing scan speed. All five powders yield parts with more than 99\% mean density at a scan speed of $1000 \mathrm{~mm} / \mathrm{s}$. The part porosity at higher scan speeds, however, increases linearly with an increasing volume fraction of coarse particles. The linear regressions in Fig. 8 fit this linear trend with a coefficient of determination $R^{2}>0.7$ for all scan speeds but $1000 \mathrm{~mm} / \mathrm{s}$. Even though the tap density of the bimodal powders is higher than that of the monomodal ones, no increase in final part density can be observed for bimodal powder blends. Also, the decrease in flowability of the bimodal powders is not reflected in the part densities in Fig. 8. Within the range of tested powders, the part density only depends on the volume fraction of coarse and fine powder and not on the powder densities or flowability. These findings are supported by the results of Coe and Pasebani [13], who found an increase of part density for bimodal powders when compared to parts made from the coarse fraction for low energy densities.

Figure 9 shows the top surfaces of cubes made from all powders at 1000,2000 , and $3000 \mathrm{~mm} / \mathrm{s}$ scan speed. The images show, similar to previous studies [25-28], a decrease in the regularity of the melt tracks for an increasing scan speed. While $\mathrm{P} \_000$ yields, according to the categorization of [28], stable tracks at 1000 and $2000 \mathrm{~mm} / \mathrm{s}$, signs of humping appear at $3000 \mathrm{~mm} / \mathrm{s}$ scan speed. Furthermore, the images show a decrease in the regularity of the melt tracks for an increasing volume fraction of coarse powder at all scan speeds. Qiu et al. [25] found that irregularly shaped scan tracks lead to a surface roughness, which in turn causes porosity in the final part. The images in Fig. 9 suggest that the findings of Qiu et al. also apply to the experiment at hand. Coarse particles cause a fluctuation of the melt pool and, in a similar fashion, cause the porosity shown in Fig. 8.

The depth, cross-sectional area, and scan track width of 114 melt pools were measured for cubes made from all five powders at $1000 \mathrm{~mm} / \mathrm{s}$ scan speed, i.e. the top row in Fig. 9. The measurements of melt pool depth, cross-sectional area
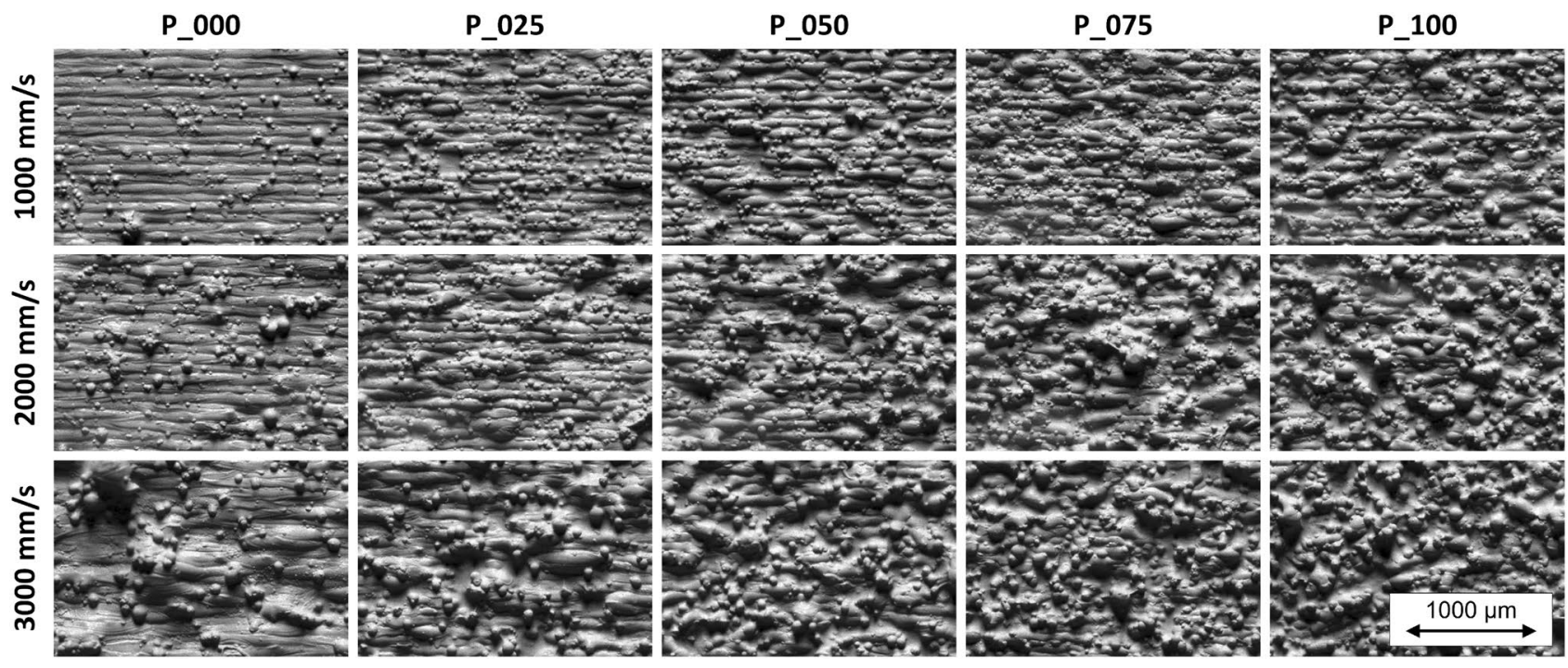

Fig. 9 Top surface images showing the scan tracks of the last layer 


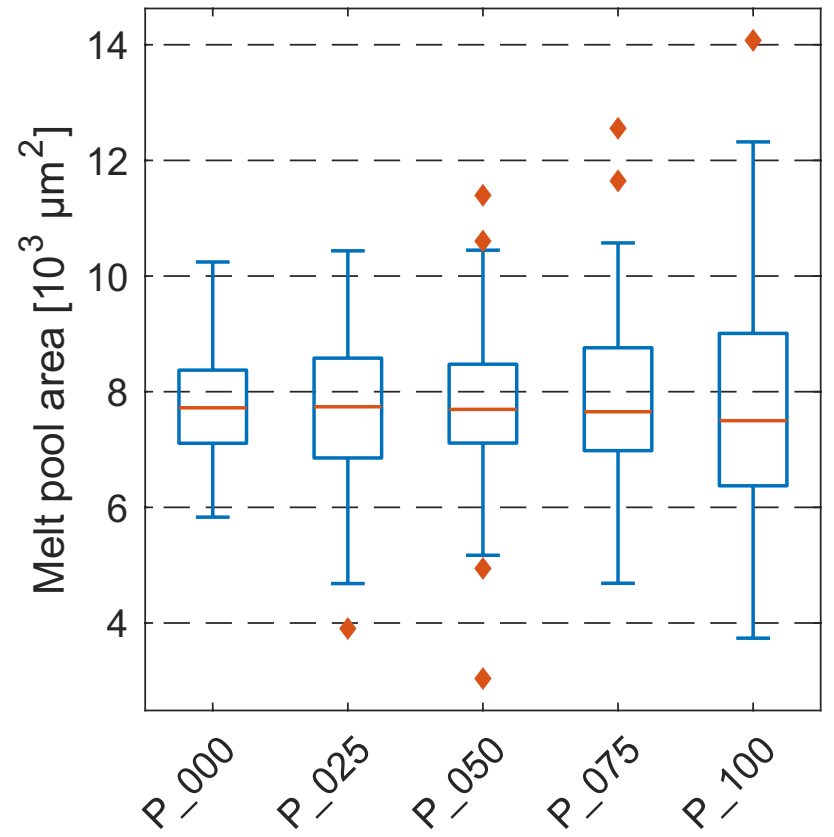

Fig. 10 Box plot of the melt pool area of parts from all five powders, manufactured at $1000 \mathrm{~mm} / \mathrm{s}$ scan speed

Table 4 Posthoc comparison of the standard deviation of the melt pool area for five cubes at $1000 \mathrm{~mm} / \mathrm{s}$ scan speed

\begin{tabular}{|c|c|c|c|c|c|}
\hline & P_000 & P_025 & P_050 & P_075 & P_100 \\
\hline P_000 & & $0.006^{*}$ & 0.920 & $0.003 *$ & $<0.001 *$ \\
\hline P_025 & & & 1 & 1 & $0.005^{*}$ \\
\hline P_050 & & & & 0.838 & $<0.001 *$ \\
\hline P_075 & & & & & $0.020 *$ \\
\hline P_100 & & & & & \\
\hline
\end{tabular}

*Shows a significant difference at the significance level $\alpha=0.05$ for the adjusted values $p^{*}=10 \times p$

and scan track width all support the finding that the regularity of the melt tracks decreases for an increasing volume fraction of P_100.

Figure 10 shows the cross-sectional area of the melt pools at $1000 \mathrm{~mm} / \mathrm{s}$ scan speed. Welch's analysis of variance showed no significant difference in the mean melt pool area between the cubes $(F(4,278.82)=0.45, p=0.77)$. A pairwise comparison of the melt pool area with Levene's test and Bonferroni correction, shown in Table 4, confirms the qualitative impression in Fig. 9. The standard deviation of the melt pool cross-sectional area increases for an increasing volume fraction of $P_{-} 100$.

Figure 11 shows the PSD of all powders before processing, as also shown in Fig. 5, and the same powders after processing, sampled from the build chamber and overflow region. The powder of the overflow region and build chamber were extracted from the machine after the build cycle, homogenized, and then measured. Therefore, the results show the average PSDs in the build chamber and overflow region. Location-dependent PSDs, e.g. at the beginning and end of the coating distance, were not measured. All PSDs were measured before sieving. Current research has shown that the effective powder layer thickness for this experiment must be assumed to be $150 \mu \mathrm{m}[16,17]$, which is relevant for the following discussion.

The results show the segregation of all powders during the coating process. The bimodal powders, however, exhibit more segregation than the monomodal ones. The segregation of powder during coating has been shown previously. Mindt et al. [29] show that a higher concentration of fine particles is deposited at the beginning of the coating distance which logically results in coarser PSD in the overflow region. These results are confirmed by experiments by Slotwinski et al. [30]. The same effect, even though not as pronounced, has also been shown experimentally by Whiting and Fox [31]. They furthermore showed that the PSD on top of parts is smaller than in the powder bed. Slotwinski et al. [30] argue that segregation happens because the larger particles are more likely to be carried away by the recoater arm. This segregation effect becomes much greater for the bimodal powders than the monomodal ones in Fig. 11, as the size difference of the particles is larger.

As the fine particles of the bimodal powders segregate during the coating process, the location dependency of the part density along the coating distance was investigated. Therefore, the location-dependent density deviation of each cube $\Delta \rho_{c i}$ from the average density $\rho_{c, \text { avg }}$ was calculated as $\Delta \rho_{c i}=\rho_{c i}-\rho_{c, \text { avg }}$, where $\rho_{c i}$ is the relative density of a cube $i$ and $\rho_{c \text {,avg }}$ is the average relative density of the five cubes made from the same powder at the same scan speed during the same build cycle, as they are shown in Fig. 2. In Fig. 12, this density deviation $\Delta \rho_{c i}$ is plotted against the location along the coating distance, according to the coordinate system in Fig. 2, for each cube. Some cubes are not included in Fig. 12, as they showed delamination defects. The Pearson correlation coefficient and the corresponding $p$ value were calculated for each powder.

Figure 12 shows a statistically significant correlation between part density deviation $\Delta \rho_{c i}$ and position along the coating distance for all powders but $\mathrm{P}_{-} 000$. Three possible explanations for this effect are (1) the segregation of powder during coating, (2) the interaction of the laser with the welding fumes, or (3) spatters.

(1) First, the porosity might be caused by the segregation of powder so that more fine particles are deposited at the beginning of the coating distance. These fine particles might then yield parts with lower porosity at the beginning of the coating distance. The location depend- 
Fig. 11 PSDs of the original powders and powders in the build chamber $(\mathrm{BC})$ and overflow region $(\mathrm{OF})$ after the build cycle. $\mathrm{P} \_000 \mathrm{BC}$ is almost identical to P_000 and therefore hard to tell apart
Fig. 12 Location dependent deviation of the part density $\Delta \rho_{c i}$ of each cube from the average density of cubes made from the same powder and at the same scanning speed $\rho_{c \text {,avg }}$, i.e. the five cubes shown in Fig. 2. Each graph represents one build cycle. The difference in density is shown in percentage points (pp). The $x$ coordinate is according to the coordinate system in Fig. 2. The Pearson correlation coefficient is reported for all plots
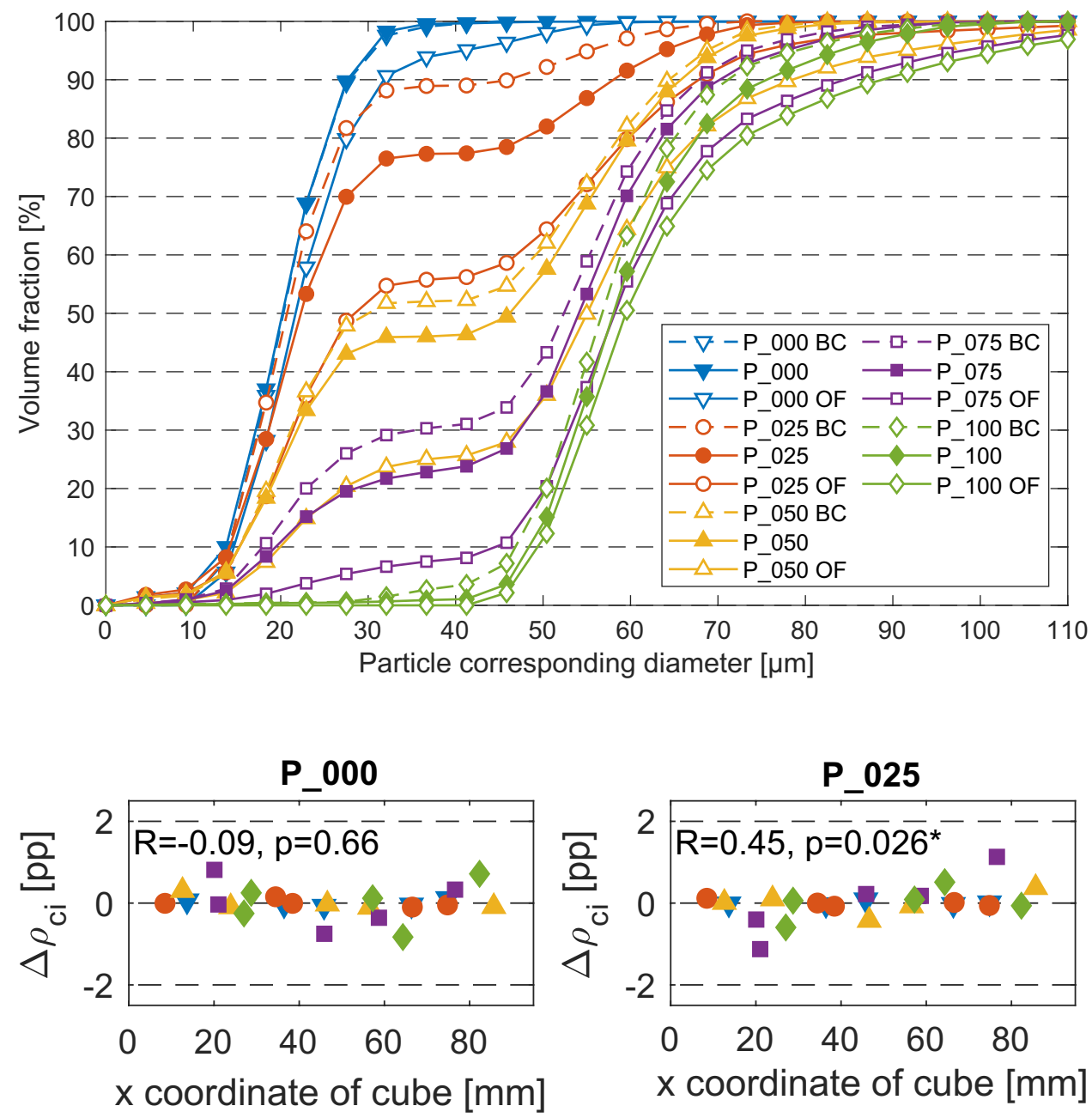

P_050

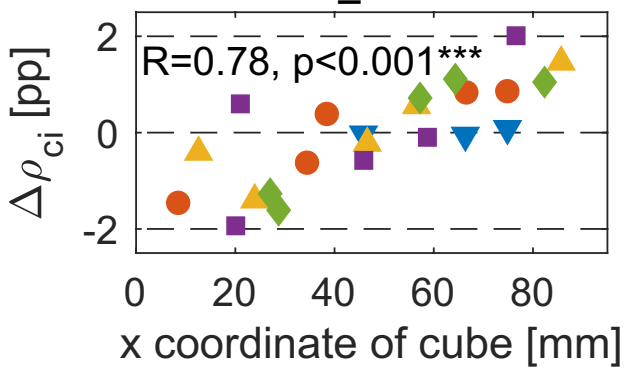

P_075

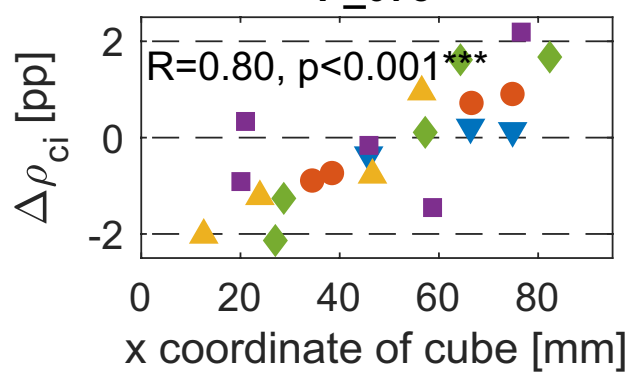

P_100

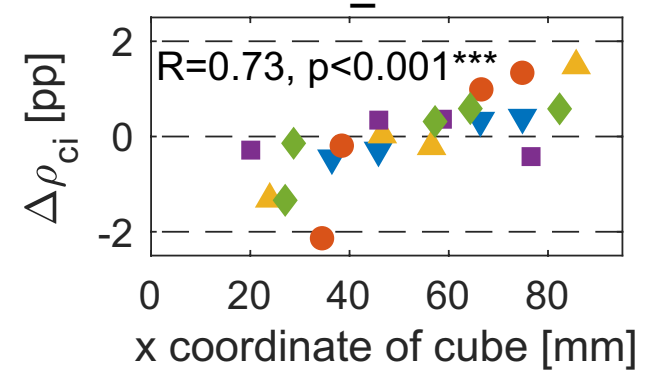

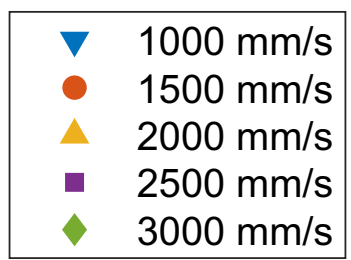


ency of the part density is, however, unlikely caused by the segregation of the powder. Only two of the three bimodal powders, P_050 and P_075, exhibit a strong density gradient. If the powder segregation was responsible for this gradient, also P_025 would also exhibit a strong density gradient, which it does not. Furthermore, does also P_100 exhibit a strong density gradient but does not segregate strongly during coating. Lastly, P_025 does exhibit a small density gradient but strong segregation during coating. Therefore, the powder segregation is unlikely to cause the density gradient along with the built plate, but it is caused by either (2) the interaction of the laser with the welding fumes or (3) spatters.

(2) Second, the laser power might be lost by scattering or attenuation of the laser by the welding plume of the melt pool [32, 33]. However, Reijonen et al. [32] have found only little location-dependent influence of the welding fumes on the part porosity and argue the increased porosity in downstream parts is more likely caused by the deposition of spatter on these parts. Therefore, welding fumes are also unlikely to be responsible for the density gradient in Fig. 12.

(3) Third, Ali et al. [34] have shown that spatter is more likely deposited at the outlet of the inert gas than at the inlet, as spatter is carried by the shielding gas. They have furthermore shown that the deposited spatter causes higher porosity in the parts downstream. This observation is also reported by Ladewig et al. [33] and Anwar and Pham [35]. This effect is most likely to be responsible for the density gradient shown in Fig. 11. However, it is not clear why P_000 is unaffected.

Overall, all powders segregate during the coating. Fine particles are more likely to be deposited during the coating process, while the large ones are swept away by the recoater. The segregation of the bimodal powders is stronger, as the size misfit between the particles is larger. There is no evidence, however, that the part density is affected by the powder segregation during this experiment.

\section{Conclusion}

The results show that the powder properties of bimodal powder blends of gas atomized 316L powder differ from those of their monomodal constituents. For the investigated blends, the tap density is higher and their flowability, measured by Hausner ratio, avalanche angle, and surface fractal, is worse. However, the final part density is unaffected by the powder flowability and density for the tested process parameters. Part density only depends on the volume fraction of coarse and fine powder and decreases approximately linearly with the volume fraction of the coarse powder. These findings have a few implications for the industry. On the one hand, no benefit of bimodal powder mixtures on part density has been found, which eliminates bimodal powders as a way to increase part quality. On the other hand, no negative influence of bimodal powders on part density was found either, which eliminates one concern when blending powders. Furthermore, the results reveal the limits for the relevance of powder flowability for part density in LPBF, as changes of flowability were not reflected in the part density of this experiment.

The mechanisms that led to part porosity were investigated. The powder-induced increase in part porosity was caused by irregularities of the melt pool, which in turn were caused by the coarse powder particles. It was shown that the powder segregates during coating because the larger particles are more likely to be carried away by the recoater arm. This segregation was stronger for the bimodal powders, as the size misfit of the particles was greater. It could, however, not be concluded that the powder segregation caused a location-dependent part porosity, e.g. lower part density at the end of the coating distance.

Funding Open Access funding provided by ETH Zurich. There was no specific funding for this research.

Data availability All data are available.

\section{Declarations}

Conflict of interest The authors declare that there is no conflict of interest regarding the publication of this article.

Open Access This article is licensed under a Creative Commons Attribution 4.0 International License, which permits use, sharing, adaptation, distribution and reproduction in any medium or format, as long as you give appropriate credit to the original author(s) and the source, provide a link to the Creative Commons licence, and indicate if changes were made. The images or other third party material in this article are included in the article's Creative Commons licence, unless indicated otherwise in a credit line to the material. If material is not included in the article's Creative Commons licence and your intended use is not permitted by statutory regulation or exceeds the permitted use, you will need to obtain permission directly from the copyright holder. To view a copy of this licence, visit http://creativecommons.org/licenses/by/4.0/.

\section{References}

1. Spierings AB, Levy G (2009) Comparison of density of stainless steel $316 \mathrm{~L}$ parts produced with selective laser melting using different powder grades. Paper presented at the Solid freeform fabrication symposium, Austin, Texas 
2. Meiners W (1999) Direktes Selektives Laser Sintern einkomponentiger metallischer Werkstoffe. PhD Thesis, RWTH Aachen, Aachen, Germany

3. Pleass C, Jothi S (2018) Influence of powder characteristics and additive manufacturing process parameters on the microstructure and mechanical behaviour of Inconel 625 fabricated by Selective Laser Melting. Addit Manuf 24:419-431. https://doi.org/10. 1016/j.addma.2018.09.023

4. Spierings AB, Herres N, Levy G (2011) Influence of the particle size distribution on surface quality and mechanical properties in AM steel parts. Rapid Prototyp J 17(3):195-202. https://doi.org/ 10.1108/13552541111124770

5. DebRoy T, Wei HL, Zuback JS, Mukherjee T, Elmer JW, Milewski JO, Beese AM, Wilson-Heid A, De A, Zhang W (2018) Additive manufacturing of metallic components - process, structure and properties. Prog Mater Sci 92:112-224. https://doi.org/10.1016/j. pmatsci.2017.10.001

6. Ali U, Mahmoodkhani Y, Imani Shahabad S, Esmaeilizadeh R, Liravi F, Sheydaeian E, Huang KY, Marzbanrad E, Vlasea M, Toyserkani E (2018) On the measurement of relative powder-bed compaction density in powder-bed additive manufacturing processes. Mater Des 155:495-501. https://doi.org/10.1016/j.matdes. 2018.06.030

7. Seyda V (2018) Werkstoff- und Prozessverhalten von Metallpulvern in der laseradditiven Fertigung. Springer, Berlin. https://doi. org/10.1007/978-3-662-58233-6_10

8. Abu-Lebdeh T, Damptey R, Lamberti V, Hamoush S (2019) Powder packing density and its impact on SLM-based additive manufacturing. In: Cham, 2019. TMS 2019 148th annual meeting \& exhibition supplemental proceedings. Springer International Publishing, pp 355-367

9. McGeary RK (1961) Mechanical packing of spherical particles. J Am Ceram Soc 44(10):513-522. https://doi.org/10.1111/j.11512916.1961.tb13716.x

10. Chen H, Wei Q, Zhang Y, Chen F, Shi Y, Yan W (2019) Powderspreading mechanisms in powder-bed-based additive manufacturing: experiments and computational modeling. Acta Mater 179:158-171. https://doi.org/10.1016/j.actamat.2019.08.030

11. Spierings AB, Voegtlin M, Bauer T, Wegener K (2016) Powder flowability characterisation methodology for powder-bed-based metal additive manufacturing. Prog Addit Manuf 1(1):9-20. https://doi.org/10.1007/s40964-015-0001-4

12. Hoeges S, Zwiren A, Schade C (2017) Additive manufacturing using water atomized steel powders. Met Powder Rep 72(2):111117. https://doi.org/10.1016/j.mprp.2017.01.004

13. Coe HG, Pasebani S (2020) Use of bimodal particle size distribution in selective laser melting of $316 \mathrm{~L}$ stainless steel. J Manuf Mater Process. https://doi.org/10.3390/jmmp4010008

14. Jeon TJ, Hwang TW, Yun HJ, VanTyne CJ, Moon YH (2018) Control of porosity in parts produced by a direct laser melting process. Appl Sci 8(12):2573. https://doi.org/10.3390/app8122573

15. Gürtler F, Karg M, Dobler M, Kohl S, Tzivilsky I, Schmidt M (2014) Influence of powder distribution on process stability in laser beam melting: analysis of melt pool dynamics by numerical simulations In: Solid freeform fabrication symposium

16. Mahmoodkhani Y, Ali U, Imani Shahabad S, Rani Kasinathan A, Esmaeilizadeh R, Keshavarzkermani A, Marzbanrad E, Toyserkani E (2019) On the measurement of effective powder layer thickness in laser powder-bed fusion additive manufacturing of metals. Prog Addit Manuf 4(2):109-116. https://doi.org/10.1007/ s40964-018-0064-0

17. Wischeropp TM, Emmelmann C, Brandt M, Pateras A (2019) Measurement of actual powder layer height and packing density in a single layer in selective laser melting. Addit Manuf 28:176-183. https://doi.org/10.1016/j.addma.2019.04.019
18. ISO A (2015) ISO/ASTM 52900. Standard terminology for additive manufacturing - general principles - terminology. https://doi. org/10.1520/ISOASTM52900-15

19. Bouwman AM, Bosma JC, Vonk P, Wesselingh JA, Frijlink HW (2004) Which shape factor(s) best describe granules? Powder Technol 146(1):66-72. https://doi.org/10.1016/j.powtec.2004. 04.044

20. Materials ASfTa (2018) ASTM B417 - 18, standard test method for apparent density of non-free-flowing metal powders using the Carney funnel. ASTM, West Conshohocken, PA, USA. https:// doi.org/10.1520/B0417-18

21. Materials ASfTa (2015) B527-15 standard test method for tap density of metal powders and compounds. ASTM, West Conshohocken, PA, USA. https://doi.org/10.1520/B0527-15

22. Amado AF (2016) Characterization and prediction of SLS processability of polymer powders with respect to powder flow and part warpage. ETH Zurich, Zurich

23. Du W, Singh M, Singh D (2020) Binder jetting additive manufacturing of silicon carbide ceramics: development of bimodal powder feedstocks by modeling and experimental methods. Ceram Int 46(12): 19701-19707. https://doi.org/10.1016/j.ceramint.2020. 04.098

24. Karapatis NP, Egger G, Gygax PE, Glardon R (1999) Optimization of powder layer density in selective laser sintering. In: 10th Solid freeform fabrication symposium (SFF), AUSTIN, TX, USA. https://doi.org/10.26153/tsw/746

25. Qiu C, Panwisawas C, Ward M, Basoalto HC, Brooks JW, Attallah MM (2015) On the role of melt flow into the surface structure and porosity development during selective laser melting. Acta Mater 96:72-79. https://doi.org/10.1016/j.actamat.2015.06.004

26. Gong H, Rafi K, Gu H, Starr T, Stucker B (2014) Analysis of defect generation in Ti-6Al-4V parts made using powder bed fusion additive manufacturing processes. Addit Manuf 1-4:87-98. https://doi.org/10.1016/j.addma.2014.08.002

27. Li R, Liu J, Shi Y, Wang L, Jiang W (2012) Balling behavior of stainless steel and nickel powder during selective laser melting process. Int J Adv Manuf Technol 59(9):1025-1035. https://doi. org/10.1007/s00170-011-3566-1

28. Gunenthiram V, Peyre P, Schneider M, Dal M, Coste F, Fabbro R (2017) Analysis of laser-melt pool-powder bed interaction during the selective laser melting of a stainless steel. J Laser Appl. https://doi.org/10.2351/1.4983259

29. Mindt HW, Megahed M, Lavery NP, Holmes MA, Brown SGR (2016) Powder bed layer characteristics: the overseen first-order process input. Metall Mater Trans A 47(8):3811-3822. https://doi. org/10.1007/s11661-016-3470-2

30. Slotwinski JA, Garboczi EJ, Stutzman PE, Ferraris CF, Watson SS, Peltz MA (2014) Characterization of metal powders used for additive manufacturing. J Res Natl Inst Stand Technol 119:460 493. https://doi.org/10.6028/jres.119.018

31. Whiting J, Fox J (2016) Characterization of feedstock in the powder bed fusion process: sources of variation in particle size distribution and the factors that influence them. Paper presented at the Proceedings of the Solid freeform fabrication symposium, Austin, Texas

32. Reijonen J, Revuelta A, Riipinen T, Ruusuvuori K, Puukko P (2020) On the effect of shielding gas flow on porosity and melt pool geometry in laser powder bed fusion additive manufacturing. Addit Manuf 32:101030. https://doi.org/10.1016/j.addma.2019. 101030

33. Ladewig A, Schlick G, Fisser M, Schulze V, Glatzel U (2016) Influence of the shielding gas flow on the removal of process by-products in the selective laser melting process. Addit Manuf 10:1-9. https://doi.org/10.1016/j.addma.2016.01.004

34. Ali U, Esmaeilizadeh R, Ahmed F, Sarker D, Muhammad W, Keshavarzkermani A, Mahmoodkhani Y, Marzbanrad E, Toyserkani E 
(2019) Identification and characterization of spatter particles and their effect on surface roughness, density and mechanical response of 17-4 PH stainless steel laser powder-bed fusion parts. Mater Sci Eng A 756:98-107. https://doi.org/10.1016/j.msea.2019.04. 026

35. Anwar AB, Pham Q-C (2017) Selective laser melting of AlSi10Mg: effects of scan direction, part placement and inert gas flow velocity on tensile strength. J Mater Process Technol 240:388-396. https://doi.org/10.1016/j.jmatprotec.2016.10.015
Publisher's Note Springer Nature remains neutral with regard to jurisdictional claims in published maps and institutional affiliations. 